\title{
A Placebo-Controlled, Single-Blind Study to Determine the Appropriate Alendronate Dosage in Postmenopausal Japanese Patients with Osteoporosis
}

\author{
The Alendronate Research Group \\ Masataka SHIRAKI, KazUhiro KUSHIDA*, Masao FUKUNAGA**, HideaKi KISHIMOTO***, \\ KIYoshi KANEDA\# , Hiroshi MINAGUCHI"\# , TETSUO INOUE*, AKIO TOMITA"\#\# , \\ YuKIHIRO NAGATA $\$$, MitSUYOSHI NAKASHIMA\$§, AND HAJIME ORIMO§\$§ \\ Department of Laboratory Medicine, Tokyo Metropolitan Geriatric Hospital, Tokyo 173, \\ * Department of Orthopedic Surgery, Hamamatsu University School of Medicine, Hamamatsu 431-31, \\ ** Department of Radioisotope, Kawasaki Medical School, Kurashiki 701-01, \\ ***Department of Orthopedic Surgery, Faculty of Medicine, Tottori University, Yonago 683, \\ \# Department of Orthopedic Surgery, Hokkaido University School of Medicine, Sapporo 060, \\ \#\# Department of Obstetrics and Gynecology, Yokohama City University School of Medicine, Yokohama 236, \\ \#\# Department of Clinical Laboratories, Aichi Medical University, Aichi 480-11, \\ ${ }^{\S}$ Department of Obstetrics and Gynecology, Faculty of Medicine, Kagoshima University, Kagoshima 890, \\ ${ }^{\$}$ Department of Pharmacology, Hamamatsu University School of Medicine, Hamamatsu 431-31, and \\ ${ }^{\$ \$}$ Department of Geriatrics, Faculty of Medicine, The University of Tokyo, Tokyo 113, Japan
}

\begin{abstract}
Alendronate (4-amino-1-hydroxybutylidene-1,1-bisphosphonate) is a potent inhibitor of bone resorption. The efficacy and safety of 36 weeks of treatment with alendronate were evaluated in Japanese women with osteoporosis, osteoporotic osteopenia or artificial menopause. The bone mineral density (BMD) of the lumbar vertebrae, markers of bone and calcium metabolism and clinical symptoms were monitored. A total of 113 randomly selected patients with osteoporosis or osteopenia were enrolled in the study, of whom 12 were excluded from the analyses because of lack of data. As a result, 101 patients were evaluated for the safety of the drug. Since eight patients were excluded from the efficacy analysis, 93 were evaluated. The incidence of adverse effects in the placebo $(\mathrm{P})$, alendronate 2.5 $\mathrm{mg} /$ day $(\mathrm{L})$ and alendronate $10 \mathrm{mg} /$ day $(\mathrm{H})$ groups increased with increasing dose of alendronate, being $6.1,14.3$ and $18.2 \%$, respectively. The most common adverse effects were gastrointestinal symptoms, none of which was serious. Lumbar BMD increased after 36 weeks of drug administration to $5.21 \%, 5.64 \%$ and $-0.90 \%$ in the $\mathrm{L}, \mathrm{H}$ and $\mathrm{P}$ groups, respectively $(P<0.001, \mathrm{~L}$ vs. $\mathrm{P}$ and $\mathrm{H}$ vs. $\mathrm{P})$. Serum alkaline phosphatase activity, serum osteocalcin and urinary deoxypyridinoline excretion were significantly decreased in a dose-related manner. Serum calcium and phosphorus were also significantly decreased after alendronate administration. Serum intact PTH was transiently increased. The present results indicate that alendronate effectively decreases bone turnover in a dose-related manner and increases lumbar BMD at a dosage of $2.5 \mathrm{mg} /$ day, the lowest dose used in this study, in Japanese patients with osteoporosis.
\end{abstract}

Key words: Osteoporosis, Bone mineral density, Bone metabolic markers, Alendronate, Asian

(Endocrine Journal 45: 191-201, 1998)

Received: June 23, 1997

Accepted: December 3, 1997

Correspondence to: Dr. Masataka SHIRAKI, Chief, Research Institute and Practice for Involutional Diseases, 1610-1 Meisei, Misato-mura, Minamiazumi-gun, Nagano Prefecture 399-81, Japan
OSTEOPOROSIS, which is characterized by loss of bone mass and microarchitectural deterioration [1], mainly affects the elderly. Bone fractures resulting from bone loss and from increasing bone 
fragility cause impairment of daily activities in this population. The primary endpoint of treating osteoporosis is therefore the prevention of bone fracture, but demonstrating a prophylactic effect of treatment on fracture may require a long observation period and a large sample size [2].

For this reason, the clinical efficacy of therapy for osteoporosis is usually assessed by measuring bone mineral density, which is directly related to the incidence of bone fracture [3]. Measurement of bone mineral density is especially useful during the early phase of drug development.

In Japan, several preparations such as active vitamin $\mathrm{D}_{3}$ analogues [4, 5], calcitonin [6], vitamin $\mathrm{K}_{2}$ [7], ipriflavone [8], etidronate [9] and estrogen derivative [10] have been approved for the treatment of osteoporosis because these drugs increase the bone mass of patients with osteoporosis. Of these preparations, etidronate, a derivative of bisphosphonate, has been reported to be a potent inhibitor of bone resorption [11]. This compound had been reported to increase in lumbar bone mineral density by $2.4 \%$ from baseline and to decrease in serum osteocalcin significantly [9]. Recently, alendronate, a more potent inhibitor of bone resorption than etidronate [12], was shown to have a significant preventative effect on fracture in a large-scale study of Caucasian patients with osteoporosis [13]. Furthermore, alendronate increased lumbar bone mineral density by about $4 \%$ from the baseline at a daily dose of $5 \mathrm{mg} /$ day [13]. The treatment of osteoporosis with alendronate has been known to induce marked decrease in bone turnover [14]. Although alendronate is expected to be used for the treatment of osteoporosis, its clinical efficacy has not been studied yet in the Asian population.

In the present study, we determined the effects of alendronate on bone mineral density and bone metabolic markers and evaluated the safety of the drug in Japanese patients with osteoporosis.

\section{Methods and Subjects}

\section{Methods}

The dose-response effects of alendronate were determined with alendronate $2.5-\mathrm{mg}$ tablets, alendronate $10-\mathrm{mg}$ tablets and placebo tablets that were identical in appearance. Three groups of patients were given either a $2.5-\mathrm{mg}$, a $10-\mathrm{mg}$ or a placebo tablet once daily in the early morning after overnight fasting; the duration of treatment was 36 weeks. In all of the groups, calcium lactate was administered concomitantly as a basic medication at a dose of $2.3 \mathrm{~g}$ (300 $\mathrm{mg}$ as elemental calcium) once daily after the evening meal. The patients were allocated to one of the three dose groups in the order of enrollment at each medical institution according to randomized drug numbers enclosed in envelopes, which were opened as the patients enrolled in the study. The investigational products were supplied by Banyu Pharmaceutical Co., Ltd. and Teijin Limited.

\section{Patient selection criteria}

The patients were selected from three populations of Japanese women. One of the populations was women with an osteoporosis score of 4 or higher according to the diagnostic criteria established by the Study Group of Osteoporosis authorized by the Ministry of Health and Welfare [15]. From this population, outpatients aged less than 75 years were enrolled in the study. To minimize error in bone density measurement, women whose bone density was less than $0.6 \mathrm{~g} / \mathrm{cm}^{2}$ (QDR-1000 equivalent [16]) were excluded from the study.

The second population was women diagnosed as having postmenopausal osteopenia. From this population, women were enrolled within five years after natural menopause if lumbar bone density was $0.6-0.88 \mathrm{~g} / \mathrm{cm}^{2}$ [16].

The third population was women who had undergone artificial menopause. From this population, women were enrolled within three years after artificial menopause if they had not been subjected to radiation therapy.

Patients with the potential to develop secondary osteoporosis or undesirable complications such as liver and renal disorders were excluded from the study.

The study protocol was reviewed by the Institutional Review Board of each participating institution. Prior to enrollment, all of the patients gave their consent to participate in the study after being provided with sufficient information about the study and related matters. 


\section{Monitored items}

At the start of observation, thoracic and lumbar vertebrae roentgenograms were obtained and lumbar bone density was measured by dual energy X-ray absorptiometry (DXA). Lumbar bone mineral density was converted to the QDR-1000 equivalent value by means of the cross-calibration equation previously reported [16]. Other monitored parameters were serum Al-p, calcium (Ca), phosphorus (Pi), N-osteocalcin (ELISA; Teijin, Japan [17]) and intact PTH (Nicols, USA [18]), and urinary calcium $(\mathrm{Ca})$, phosphorus $(\mathrm{Pi})$, creatinine and deoxypyridinoline [19]. The urinary concentrations of deoxypyridinoline were measured by HPLC [19]. Serum and urine samples were obtained $0,4,8,12$, 24 and 36 weeks after treatment and the levels of the above mentioned parameters were measured at Teijin Bio Laboratories.

To evaluate the safety of alendronate, urinalysis was conducted and peripheral blood cell counts, hepatic and renal parameters, creatinine phosphokinase (CPK), cholesterol, $\mathrm{Na}, \mathrm{K}$ and $\mathrm{Cl}$ were monitored.

Subjective symptoms such as low back pain and other symptoms related to drug administration (adverse effects) were also monitored.

\section{Data analysis}

In each of the dose groups, the significance of changes from the baseline in bone density and bone metabolic parameters was examined by the rate of change at each evaluation point by using the Student's $t$-test (two-tailed) or the signed rank sum test (multiplicity was adjusted by Bonferroni type). Differences between the groups were analyzed by Fisher's restricted LSD test.

Prior to data analysis, the bone density measurement data were examined for reliability by the Bone Mass Assessment Committee, generally according to the method reported previously [5].

All of the data were expressed as the mean \pm SEM, except for the case of adjusted means.

\section{Data handling and study sites}

The handling of data from individual patients, i.e., determining which patients should be included in or excluded from the data analysis, was the responsibility of the Central Committee, presided over by the chief investigator Hajime Orimo, M.D. (Department of Geriatrics, University of Tokyo) and including the controller Mitsuyoshi Nakashima, M.D. (Department of Pharmacology, Hamamatsu University School of Medicine). Bone density measurement data were examined for reliability by the Bone Mass Assessment Committee and were excluded from analysis when judged unreliable. The Committees maintained blindness to the dose of alendronate while deliberating on the data handling.

The study was performed from September, 1991 to May, 1993 in 32 departments of 22 medical institutions nationwide.

\section{Results}

\section{Data handling}

The three populations of patients were pooled to examine the dose-response effects of alendronate. Further, to examine the effects of alendronate on bone density, the osteoporotic patients and postmenopausal women were analyzed separately.

As shown in Fig. 1, a total of 113 patients were enrolled in the study, of whom 12 were excluded from all of the analyses for the reasons listed in the figure legend. Of the 101 evaluated patients, eight were excluded from the efficacy analysis because of adverse reactions in six cases and protocol violations with respect to drug administration in two. Of the 93 patients included in the efficacy analysis, 13 were excluded from the bone density analysis. Therefore, the total sample size was 80 patients for the bone density analysis, 93 patients for the efficacy analysis and 101 patients for the safety analysis. The background data of the patients are shown in Table 1. There were no significant differences between the three groups in any of the background factors except for bone density measured by dual X-ray absorptiometry (DXA), which was significantly higher $(P=0.038)$ in the placebo group (P group) than in the $2.5 \mathrm{mg} /$ day group (L group) and the $10 \mathrm{mg} /$ day group $(\mathrm{H}$ group). Therefore, the significance of the change in bone mineral density was analyzed by analysis of covariance and adjusted means. 


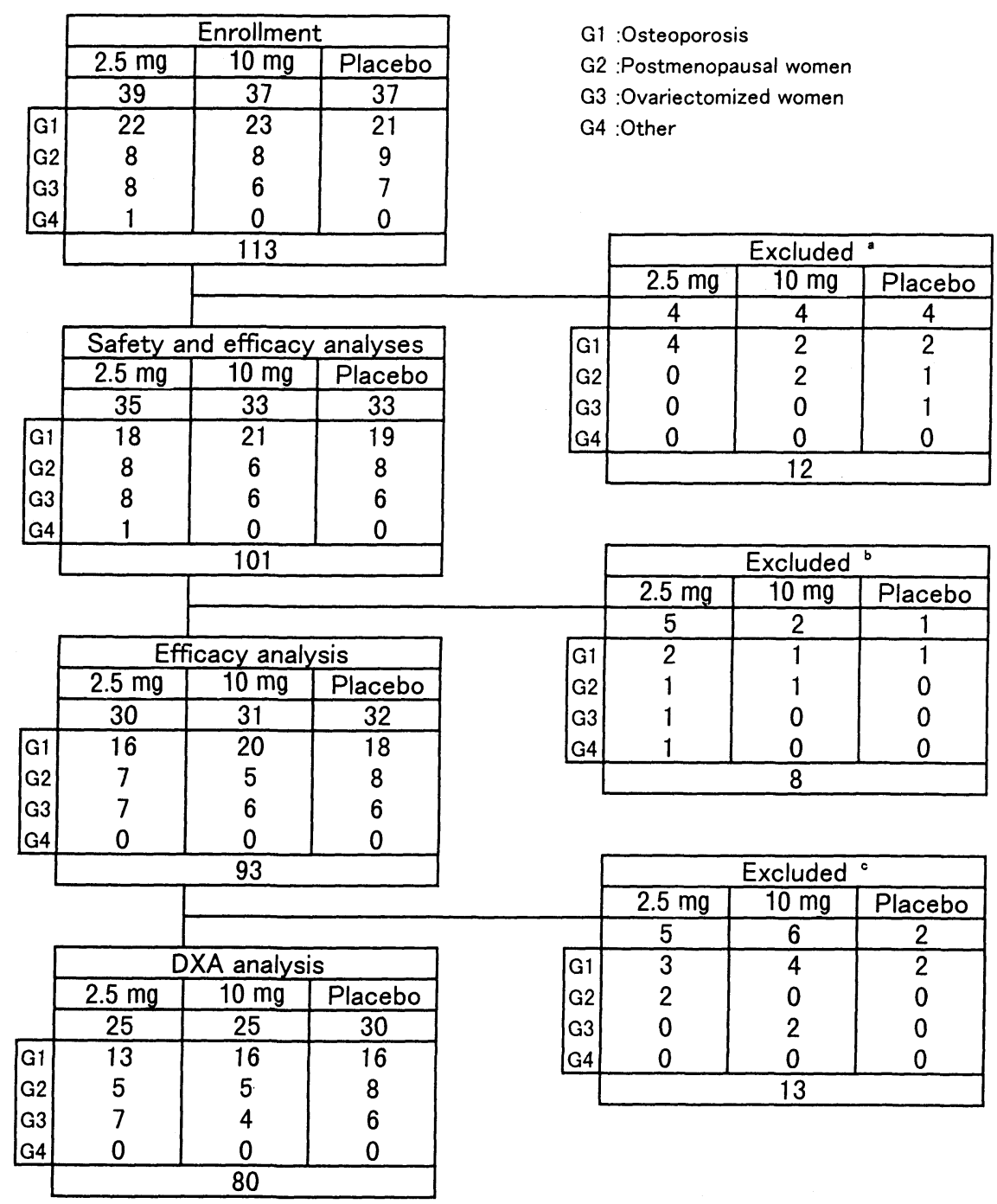

Fig. 1. a Reasons for exclusion (12 cases): Incidental disease 1 (2.5 mg: 1), Patient withdrew consent 1 (10 mg: 1), Patient's non cooperation 5 (2.5 mg: 2, $10 \mathrm{mg}: 3$ ), Patient did not visit the clinic 3 (2.5 mg: 1, Placebo: 2), IgA Myeloma 1 (Placebo: 1), Patient did not take the medication as indicated 1 (Placebo: 1), bReasons for the exclusion ( 8 cases): Adverse reactions 6 (2.5 mg: 3, $10 \mathrm{mg}: 2$, Placebo: 1 ), Protocol violation 2 ( $2.5 \mathrm{mg}: 2$ ), cReasons for exclusion (13 cases): Fracture in ROI (region of interest) 4 (10 mg: 2, Placebo: 2), Scoliosis 2 (2.5 mg: 2), Osteophyte 1 (10 mg: 1), Extra-osseous calcification 1 (2.5 mg: 1), Inadequate scan 1 (10 mg: 1), Photon overexposure 1 (10 mg: 1), Absence of data at baseline 2 (2.5 mg: 1, $10 \mathrm{mg}: 1)$, Change in DXA apparatus 1 (2.5 mg: 1 ).

\section{Safety analysis}

The safety of alendronate was evaluated based on the occurrence of clinical symptoms, the causal relationship of the symptoms with the drug, and abnormal laboratory data.

The incidence of adverse effects did not differ between the groups but tended to increase with the dose, being $6.1 \%(2 / 33), 14.3 \%(5 / 35)$ and $18.2 \%$ $(6 / 33)$ in the $\mathrm{P}, \mathrm{L}$ and $\mathrm{H}$ groups, respectively. The adverse effects occurred primarily during the first 4 weeks of treatment. Two and three patients in the $\mathrm{L}$ and $\mathrm{H}$ groups, respectively, were withdrawn from the study because of adverse effects. The incidence of abnormal laboratory data was lower 
Table 1-1. Summary of patient characteristics

\begin{tabular}{|c|c|c|c|c|c|c|}
\hline & & $2.5 \mathrm{mg}$ & $10 \mathrm{mg}$ & Placebo & Total & \multirow{2}{*}{$\chi^{2}$-test } \\
\hline & $\mathrm{n}$ & 35 & 33 & 33 & 101 & \\
\hline \multirow[t]{6}{*}{ Age (yr) } & $\sim 44$ & 3 & 3 & 4 & 10 & \multirow{6}{*}{$\begin{array}{c}\text { N.S. } \\
(P=0.599)\end{array}$} \\
\hline & $45 \sim 54$ & 14 & 8 & 9 & 31 & \\
\hline & $55 \sim 64$ & 7 & 10 & 10 & 27 & \\
\hline & $65 \sim 74$ & 11 & 10 & 7 & 28 & \\
\hline & $75 \sim$ & 0 & 2 & 3 & 5 & \\
\hline & Mean & 57.3 & 60.2 & 58.4 & & \\
\hline \multirow[t]{5}{*}{ Height $(\mathrm{cm})$} & $\sim 139$ & 0 & 1 & 0 & 1 & \multirow{5}{*}{$\begin{array}{c}\text { N.S. } \\
(P=0.306)\end{array}$} \\
\hline & $140 \sim 149$ & 10 & 10 & 16 & 36 & \\
\hline & $150 \sim 159$ & 24 & 22 & 17 & 63 & \\
\hline & $160 \sim$ & 1 & 0 & 0 & 1 & \\
\hline & Mean & 150.9 & 150.6 & 150.7 & & \\
\hline \multirow[t]{5}{*}{ Weight (kg) } & $\sim 39$ & 1 & 2 & 2 & 5 & \multirow{5}{*}{$\begin{array}{c}\text { N.S. } \\
(P=0.687)\end{array}$} \\
\hline & $40 \sim 49$ & 12 & 15 & 14 & 41 & \\
\hline & $50 \sim 59$ & 19 & 11 & 12 & 42 & \\
\hline & $60 \sim$ & 3 & 5 & 5 & 13 & \\
\hline & Mean & 51.1 & 50.4 & 51.1 & & \\
\hline \multirow[t]{4}{*}{$\mathrm{YSM}^{\mathrm{a}}(\mathrm{yr})$} & Within 3 years & 13 & 9 & 10 & 32 & \multirow{4}{*}{$\begin{array}{c}\text { N.S. } \\
(P=0.885)\end{array}$} \\
\hline & Within 5 years & 3 & 4 & 3 & 10 & \\
\hline & Over 6 years & 16 & 19 & 17 & 52 & \\
\hline & Unknown & 3 & 1 & 3 & 7 & \\
\hline \multirow[t]{3}{*}{ Ovariectomy } & No & 23 & 21 & 22 & 66 & \multirow{3}{*}{$\begin{array}{c}\text { N.S. } \\
(P=0.877)\end{array}$} \\
\hline & Yes & 11 & 12 & 10 & 33 & \\
\hline & Unknown & 1 & 0 & 1 & 2 & \\
\hline \multirow[t]{3}{*}{ Child birth } & No & 3 & 4 & 2 & 9 & \multirow{3}{*}{$\begin{array}{c}\text { N.S. } \\
(P=0.925)\end{array}$} \\
\hline & Yes & 28 & 26 & 28 & 82 & \\
\hline & Unknown & 4 & 3 & 3 & 10 & \\
\hline \multirow[t]{4}{*}{ Lactation } & No & 4 & 7 & 4 & 15 & \multirow{4}{*}{$\begin{array}{c}\text { N.S. } \\
(P=0.896)\end{array}$} \\
\hline & Breast milk & 1 & 1 & 2 & 4 & \\
\hline & Breast milk+Artificial lactation & 12 & 11 & 12 & 35 & \\
\hline & Unknown & 18 & 14 & 15 & 47 & \\
\hline \multirow[t]{4}{*}{ Milk intake } & Scarcely & 8 & 7 & 4 & 19 & \multirow{4}{*}{$\begin{array}{c}\text { N.S. } \\
(P=0.912)\end{array}$} \\
\hline & Sometime & 12 & 10 & 13 & 35 & \\
\hline & Everyday & 10 & 12 & 12 & 34 & \\
\hline & Unknown & 5 & 4 & 4 & 13 & \\
\hline \multirow[t]{4}{*}{ Diagnosis } & Osteoporosis & 18 & 21 & 19 & 58 & \multirow{4}{*}{$\begin{array}{c}\text { N.S. } \\
(P=0.823)\end{array}$} \\
\hline & Postmenopausal women & 8 & 6 & 8 & 22 & \\
\hline & Ovariectomized women & 8 & 6 & 6 & 20 & \\
\hline & Other & 1 & 0 & 0 & 1 & \\
\hline \multirow{2}{*}{$\begin{array}{l}\text { Osteoporosis } \\
\text { score }\end{array}$} & More than 5 points & 8 & 15 & 14 & 37 & \multirow{2}{*}{$\begin{array}{c}\text { N.S. } \\
(P=0.119)\end{array}$} \\
\hline & 4 points & 10 & 6 & 5 & 21 & \\
\hline \multirow{2}{*}{$\begin{array}{l}\text { Past history of } \\
\text { estrogen } \\
\text { treatment }\end{array}$} & No & 32 & 29 & 33 & 94 & \multirow{2}{*}{$\begin{array}{c}\text { N.S. } \\
(P=0.137)\end{array}$} \\
\hline & Yes & 3 & 4 & 0 & 7 & \\
\hline
\end{tabular}

aYears since menopause.

(though not significantly) in the $\mathrm{P}$ group than in the $\mathrm{L}$ group and the $\mathrm{H}$ group, being $0 \%(0 / 33)$, $14.3 \%(5 / 35)$ and $12.1 \%(4 / 33)$, respectively. No serious adverse events were observed in any of the 101 patients evaluated for safety, and tolerability was similar in all the groups (Table 2). The most 
Table 1-2. Summary of baseline parameters

\begin{tabular}{|c|c|c|c|c|}
\hline Parameter & $2.5 \mathrm{mg}$ & $10 \mathrm{mg}$ & Placebo & F-test \\
\hline Lumbar spine $\mathrm{BMD}^{\mathrm{a}} \quad\left(\mathrm{g} / \mathrm{cm}^{2}\right)$ & $\begin{array}{c}0.726 \pm 0.121 \\
(25)\end{array}$ & $\begin{array}{l}0.710 \pm 0.114 \\
(25)\end{array}$ & $\begin{array}{l}0.785 \pm 0.108 \\
(30)\end{array}$ & $P=0.038^{*}$ \\
\hline Lumbar spine $\mathrm{BMD}^{\mathrm{b}} \quad\left(\mathrm{g} / \mathrm{cm}^{2}\right)$ & $\begin{array}{c}0.663 \pm 0.102 \\
(13)\end{array}$ & $\begin{array}{c}0.653 \pm 0.093 \\
(16)\end{array}$ & $\begin{array}{c}0.723 \pm 0.069 \\
(16)\end{array}$ & $P=0.070$ \\
\hline Lumbar spine $\mathrm{BMD}^{\mathrm{c}} \quad\left(\mathrm{g} / \mathrm{cm}^{2}\right)$ & $\begin{array}{c}0.794 \pm 0.105 \\
\quad(12)\end{array}$ & $\begin{array}{c}0.813 \pm 0.064 \\
\text { (9) }\end{array}$ & $\begin{array}{c}0.856 \pm 0.103 \\
(14)\end{array}$ & $P=0.272$ \\
\hline Serum Al-p & $\begin{array}{c}121.00 \pm 63.94 \\
(33)\end{array}$ & $\begin{array}{l}123.81 \pm 69.09 \\
\quad(31)\end{array}$ & $\begin{array}{c}133.10 \pm 68.65 \\
(30)\end{array}$ & $P=0.767$ \\
\hline Serum calcium & $\begin{array}{c}9.368 \pm 0.547 \\
(34)\end{array}$ & $\begin{array}{c}9.419 \pm 0.622 \\
(32)\end{array}$ & $\begin{array}{c}9.313 \pm 0.439 \\
(30)\end{array}$ & $P=0.799$ \\
\hline Serum phoshorus & $\begin{array}{l}3.518 \pm 0.616 \\
\quad(34)\end{array}$ & $\begin{array}{c}3.626 \pm 0.373 \\
(31)\end{array}$ & $\begin{array}{l}3.634 \pm 0.426 \\
\quad(29)\end{array}$ & $P=0.529$ \\
\hline Serum intact $\mathrm{PTH}$ & $\begin{array}{c}32.233 \pm 16.128 \\
(30)\end{array}$ & $\begin{array}{c}28.567 \pm 12.514 \\
(30)\end{array}$ & $\begin{array}{c}30.806 \pm 15.986 \\
(31)\end{array}$ & $P=0.709$ \\
\hline Serum N-osteocalcin $(\mathrm{ng} / \mathrm{ml})$ & $\begin{array}{c}12.957 \pm 4.967 \\
(30)\end{array}$ & $\begin{array}{c}11.960 \pm 4.896 \\
(30)\end{array}$ & $\begin{array}{c}13.990 \pm 6.321 \\
(31)\end{array}$ & $P=0.455$ \\
\hline Urine calcium $/ \mathrm{Cr}$ & $\begin{array}{c}0.099 \pm 0.041 \\
(30)\end{array}$ & $\begin{array}{c}0.108 \pm 0.052 \\
(28)\end{array}$ & $\begin{array}{l}0.104 \pm 0.058 \\
\quad(31)\end{array}$ & $P=0.858$ \\
\hline Urine phosphorus/Cr & $\begin{array}{l}0.732 \pm 0.375 \\
(30)\end{array}$ & $\begin{array}{c}0.643 \pm 0.304 \\
(28)\end{array}$ & $\begin{array}{c}0.749 \pm 0.321 \\
(31)\end{array}$ & $P=0.447$ \\
\hline $\begin{array}{l}\text { Urine deoxypyridinoline } / \mathrm{Cr} \\
\qquad(\mathrm{pmol} / \mu \mathrm{mol})\end{array}$ & $\begin{array}{c}8.573 \pm 3.823 \\
(30)\end{array}$ & $\begin{array}{c}8.193 \pm 3.286 \\
(28)\end{array}$ & $\begin{array}{c}9.148 \pm 3.393 \\
(31)\end{array}$ & $P=0.385$ \\
\hline
\end{tabular}

a, All patients; b, Osteoporosis; c, Postmenopausal women. Mean \pm S.D. (N). ${ }^{*} P<0.05$.

Table 2. Adverse events

\begin{tabular}{lcccc}
\hline & Total & $2.5 \mathrm{mg}$ & $10 \mathrm{mg}$ & Placebo \\
\hline Evaluable: Total $^{*}$ & 101 & 35 & 33 & 33 \\
\hline Adverse effects: Total $^{*}$ & 13 & 5 & 6 & 2 \\
Stomachache & 3 & 1 & 1 & 1 \\
Stomachache, Nausea & 1 & 0 & 1 & 0 \\
Nausea, Vomiting & 1 & 1 & 0 & 0 \\
Nausea, Headache & 1 & 0 & 1 & 0 \\
Anorexia & 1 & 0 & 1 & 0 \\
Constipation & 1 & 0 & 1 & 0 \\
Headache & 2 & 1 & 0 & 1 \\
Headache, Malaise & 1 & 1 & 0 & 0 \\
Rash, Itching & 1 & 0 & 1 & 0 \\
Arthralgia of fingers & 1 & 1 & 0 & 0 \\
\hline Abnormal laboratory data: Total ${ }^{*}$ & 9 & 5 & 4 & 0 \\
decreased serum Ca & 1 & 1 & 0 & 0 \\
decreased Al-p\# & 2 & 1 & 1 & 0 \\
increased ALT & 1 & 1 & 0 & 0 \\
increased ALT and AST & 1 & 0 & 1 & 0 \\
increased ALT, AST, LDH and total cholesterol & 1 & 1 & 0 & 0 \\
increased LDH & 2 & 1 & 1 & 0 \\
increased LDH and K & 1 & 0 & 1 & 0 \\
\hline
\end{tabular}

*Number of patients, \#Alkaline phosphatase. 


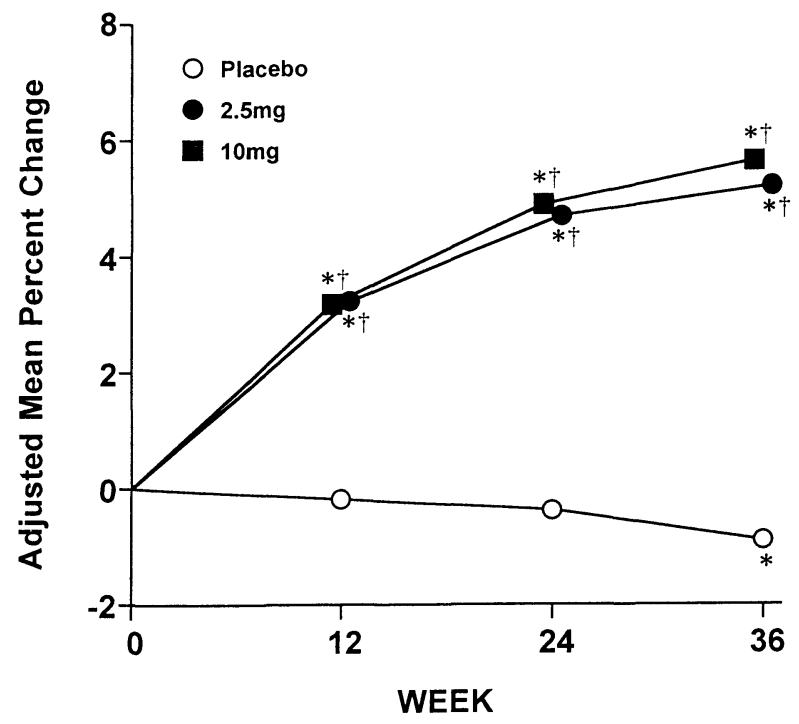

Fig. 2. The time course change in lumbar bone mineral density. Each point indicates the adjusted mean percent change from the baseline value. ${ }^{*} P<0.017$ for comparison with the baseline. $\dagger P<0.05$ for comparison with the placebo.

common adverse effects were gastrointestinal symptoms that did not appear to be any more prevalent in the alendronate group than in the placebo group.

\section{Changes in bone density}

Changes in bone mineral density were examined by per-protocol analysis in all evaluable patients $(n=80)$ and were further analyzed in the following subgroups: patients diagnosed as having osteoporosis $(n=45)$ and postmenopausal women $(n=35)$. In the entire evaluable population, bone density increased after 36 weeks of treatment in the $\mathrm{L}$ group and the $\mathrm{H}$ group, with the rate of increase being $5.21 \%(n=19)$ and $5.64 \%(n=19)$ from baseline (adjusted mean), respectively. In contrast, bone density decreased by $-0.90 \%(n=21)$ in the $P$ group (adjusted mean) (Fig. 2). Although the increases in the $\mathrm{L}$ group and the $\mathrm{H}$ group were greater than the change in the $P$ group $(P<0.001)$, there was no significant difference between the $L$ group and the $\mathrm{H}$ group in the increase (Fig. 2). Similarly, in the subpopulations of osteoporotic patients and postmenopausal women, bone density increased more in the $\mathrm{L}$ and $\mathrm{H}$ groups than in the $P$ group, but the response observed in osteoporotic

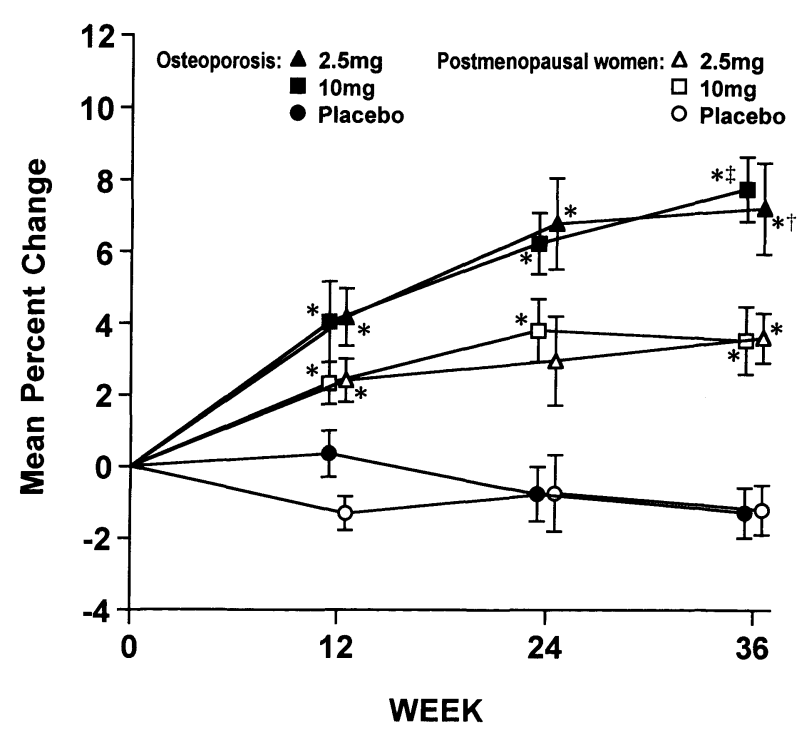

Fig. 3. The time course change in lumbar bone mineral density among osteoporosis and postmenopausal women on the placebo (circles), $2.5 \mathrm{mg}$ (triangles) and $10 \mathrm{mg}$ (squares) groups. Each point indicates the mean percent change and the bars on the point are SEM. $* P<0.017$ for comparison with the baseline. $+P<0.05$ for comparison with the postmenopausal women $(2.5 \mathrm{mg})$. $\$ P<0.05$ for comparison with the postmenopausal women $(10 \mathrm{mg})$.

patients $(+7.2 \%, \mathrm{n}=10$ for $\mathrm{L}$ and $+7.7 \%, \mathrm{n}=10$ for $\mathrm{H})$ was greater than that observed in postmenopausal women $(+3.6 \%, \mathrm{n}=9$ for $\mathrm{L}$ and $+3.5 \%, \mathrm{n}=9$ for $\mathrm{H}$; $P<0.05$ ) (Fig. 3).

\section{Changes in biochemical parameters}

Changes in serum levels of $\mathrm{Ca}, \mathrm{Pi}$ and $\mathrm{Ca}$ regulating hormones: The serum $\mathrm{Ca}$ level decreased significantly in the $\mathrm{L}$ and $\mathrm{H}$ groups, showing a maximum rate of change of $-3.2 \pm 5.5 \%(n=24)$ at week 36 in the $L$ group $(P=0.009)$ and $-3.2 \pm 6.2 \%$ $(\mathrm{n}=26)$ at week 12 in the $\mathrm{H}$ group $(P=0.015)$. In contrast, the serum level of $\mathrm{Ca}$ in the $\mathrm{P}$ group decreased by $-1.7 \pm 5.1 \% \quad(n=20)$ at week 36 $(P=0.161)$. The serum Pi level decreased significantly in the $\mathrm{L}$ and $\mathrm{H}$ groups, with the maximum rate of change from the baseline value being $-8.0 \pm 15.7 \%(n=23)$ at week 36 in the $L$ group $(P=0.024)$ and $-10.7 \pm 13.9 \%(\mathrm{n}=24)$ at week 4 in the $\mathrm{H}$ group $(P=0.001)$.

Urinary $\mathrm{Ca}$ excretion decreased in the $\mathrm{L}$ and $\mathrm{H}$ groups, with a rate of change of about $-20 \pm 50 \%$ 
between week 4 and week 12 . Similarly, serum intact PTH showed a marked transient increase in the $\mathrm{L}$ ( $44 \pm 74 \% ; \mathrm{n}=23, P=0.010$, at week 8 ) and $\mathrm{H}$

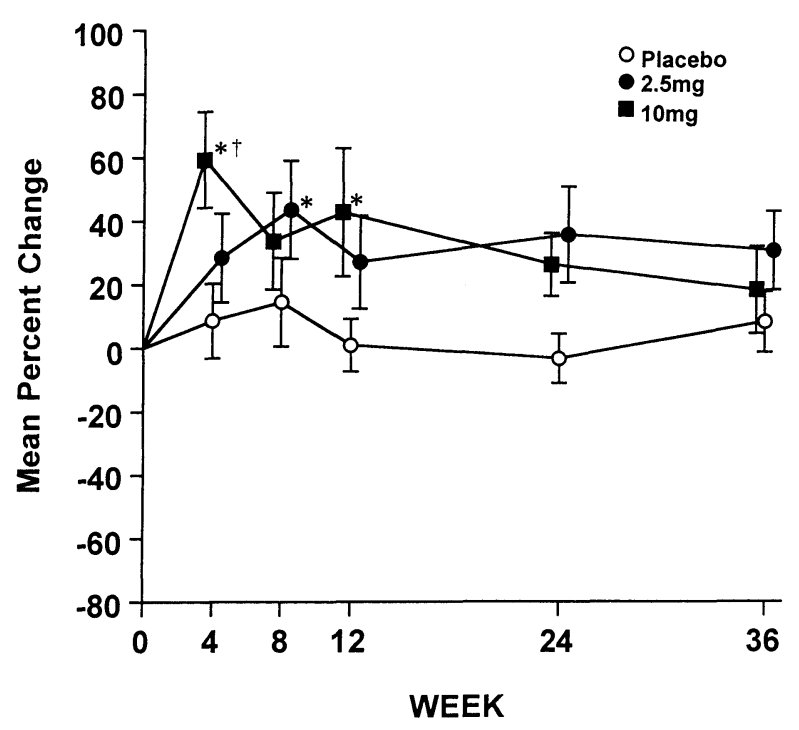

Fig. 4. The time course change in serum intact PTH. Each point indicates the mean percent change and the bars on the point are SEM. $* P<0.01$ for comparison with the baseline. $† P<0.05$ for comparison with the placebo.

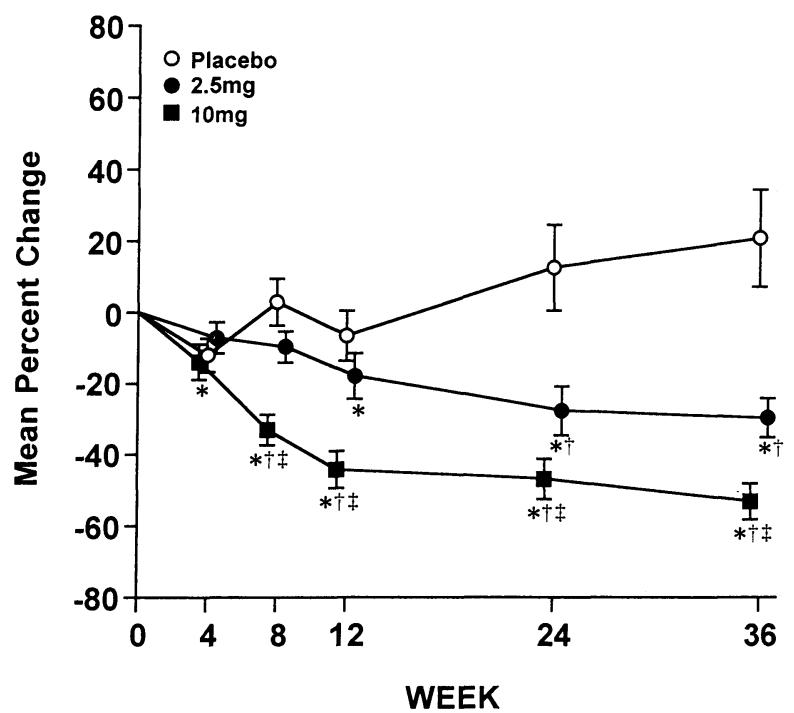

Fig. 5. The time course change in serum N-osteocalcin. Each point indicates the mean percent change and the bars on the point are SEM. ${ }^{*} P<0.01$ for comparison with the baseline. $\dagger P<0.05$ for comparison with the placebo. $\ddagger P<0.05$ for comparison with $2.5 \mathrm{mg}$.
(59 $\pm 75 \% ; n=25, P=0.001$, at week 4 ) groups between week 4 and week 12 (Fig. 4), then returned to the basal level at week 36 .

Changes in bone turnover markers: Serum Al-P activity decreased dose-dependently by $-9.2 \pm$ $15.6 \%(\mathrm{n}=18, P=0.022),-22.5 \pm 18.0 \% \quad(\mathrm{n}=23$, $P<0.001)$ and $-35.1 \pm 14.8 \%(\mathrm{n}=20, P<0.001)$ at week 36 in the $\mathrm{P}, \mathrm{L}$ and $\mathrm{H}$ groups, respectively. Serum $\mathrm{N}$-osteocalcin also decreased dose-dependently by $20.6 \pm 62.0 \%(n=21, P=0.144),-29.7 \pm 25.1 \%(n=21$, $P<0.001)$ and $-53.1 \pm 25.1 \%(n=25, P<0.001)$ at week 36 in the $\mathrm{P}, \mathrm{L}$ and $\mathrm{H}$ groups, respectively (Fig. 5), and urinary deoxypyridinoline decreased dosedependently by $-13.8 \pm 26.2 \%(\mathrm{n}=21, P=0.026)$, $-40.2 \pm 20.4 \%(\mathrm{n}=21, P<0.001)$ and $-52.4 \pm 18.3 \%$ $(\mathrm{n}=23, P<0.001)$ (Fig. 6).

\section{Discussion}

In many European countries and in the United States, alendronate is being used clinically for the treatment of osteoporosis because of its potent antiresorbing activity [12]. The effects of alendronate on bone density and fracture prevention have been established in Caucasians [13].

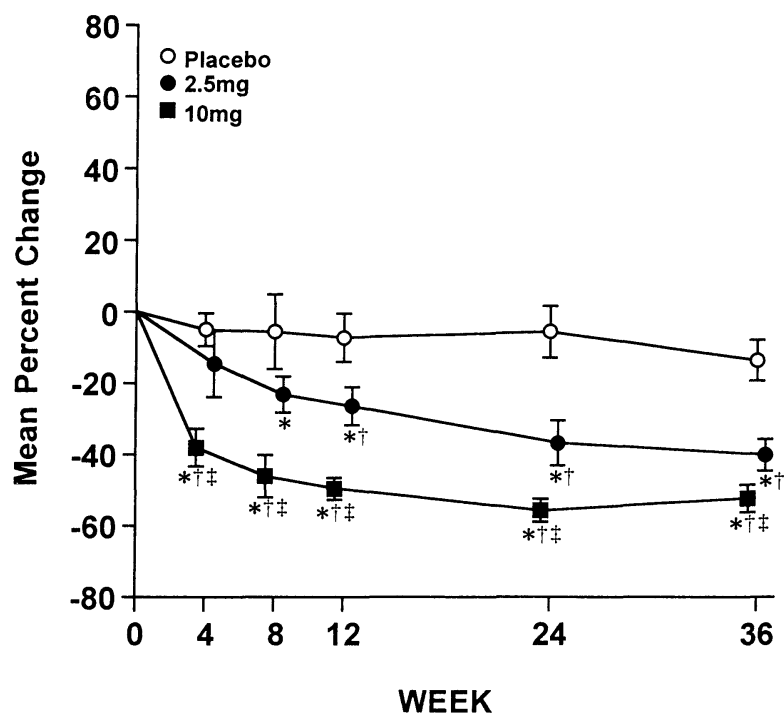

Fig. 6. The time course change in urine deoxypyridinoline/cr. Each point indicates the mean percent change and the bars on the point are SEM. $* P<0.01$ for comparison with the baseline. $\dagger P<0.05$ for comparison with the placebo. $\ddagger P<0.05$ for comparison with $2.5 \mathrm{mg}$. 
Nevertheless, the effects of alendronate in Asian populations have not previously been reported. Compared with Caucasians, Asians have a smaller body size [20] and a lower dietary intake of calcium [21]. Because of these racial differences, the recommended drug dose established for Caucasians may not be appropriate for Asians. The present small-scale, single-blind study was therefore conducted in postmenopausal Japanese women to determine the dose-response effects of alendronate and to estimate the clinical dose of the drug in the Japanese population.

The study yielded the following three major findings. First, alendronate 2.5 and $10 \mathrm{mg} /$ day significantly increased bone density not only in postmenopausal women with osteopenia but also in patients diagnosed as having osteoporosis, with no significant difference between the two dosage groups, but the percentage changes in BMD in osteopenia $(+3.6 \%$ for $\mathrm{L}$ and $+3.5 \%$ for $\mathrm{H})$ were less than those in osteoporosis $(+7.2 \%$ for $\mathrm{L}$ and $+7.7 \%$ for $\mathrm{H}$ ). This may be because the baseline bone density was higher in osteopenia than in osteoporotic patients.

Second, alendronate decreased bone turnover markers such as $\mathrm{Al}-\mathrm{P}$, osteocalcin and urinary deoxypyridinoline excretion, with significant differences between the two dosage groups in the effect.

Third, serum Ca and urinary Ca excretion were decreased by alendronate, probably because of inhibition of bone resorption.

At the same time, a corresponding transient increase was noted in the serum intact PTH level.

What must be considered is that the doseresponse effect of alendronate on bone turnover markers was not consistent with the bone density results. Alendronate had a significant doseresponse effect on bone remodeling markers at dosages of 2.5 and $10 \mathrm{mg} /$ day. This indicates that bone metabolic markers are more sensitive indices than bone density.

The effect of alendronate on bone density has been reported to increase continuously without saturation during one to two years of administration in European and American populations [22].

A dose-response effect on bone density will therefore probably be observed in Japanese women in further investigations involving longer periods of administration.
The clinical dose of alendronate is $10 \mathrm{mg}$ /day in Caucasians [13]. In the Japanese women who participated in the present study, the bone-densityincreasing effect of alendronate was not significantly different at daily doses of 2.5 and 10 mg.

This indicates that alendronate will be efficacious at a lower dose in Japanese than in Caucasian populations.

We administered a calcium preparation at a dosage of $300 \mathrm{mg} /$ day of elemental calcium to all of the patients as a basic medication, based primarily on ethical consideration of the patients receiving a placebo and also to inhibit excessive secondary hyperparathyroidism that may occur because of excessive inhibition of bone resorption, but a transient increase in intact PTH was still observed with a significant decrease in serum $\mathrm{Ca}$ in patients receiving alendronate 2.5 and $10 \mathrm{mg}$ / day. This phenomenon has also been observed in Caucasian populations and suggests that, similarly to estrogen [23], alendronate characteristically induces a transient secondary hyperparathyroidism independently of regular Ca intake [22].

Secondary metabolic changes may explain the transient increase in intact PTH. For instance, increased PTH secretion promotes the production of $1,25(\mathrm{OH})_{2}-\mathrm{D}$ [23] when the vitamin $\mathrm{D}$ activation mechanism is functionally normal.

Although the mechanism of the increase in intact PTH during the administration of alendronate has not been elucidated, it can be concluded that no excessive secondary hyperparathyroidism will be induced in Japanese patients if a calcium preparation is given concomitantly at a dosage of $300 \mathrm{mg} /$ day.

\section{Conclusions}

Alendronate significantly increased bone density and noticeably reduced the level of bone turnover markers in postmenopausal Japanese women when administered at doses of 2.5 and $10 \mathrm{mg} /$ day for 36 weeks. No particular safety concerns were noted during the 36-week treatment period.

Based on these results, the positive effect of alendronate on bone density can be hypothesized at a lower dose in Japanese than in Caucasian patients. 


\section{References}

1. Christiansen C (1993) Proceedings of the Consensus Development Conference on Osteoporosis, Hong Kong, April 1-2. Am J Med 95 (Suppl 5A): 1S-78S.

2. Black DM, Reiss TF, Nevitt MC, Cauley J, Karpf D, Cummings SR (1993) Design of the fracture intervention trial. Osteoporosis Int Suppl 3: S29-39.

3. Cummings SR, Black DM, Nevitt MC, Browner W, Cauley J, Ensrud K, Genant HK, Palermo L, Scott J, Vogt TM (1993) Bone density at various sites for prediction of hip fractures. Lancet 341: 72-75.

4. Orimo H, Shiraki M, Hayashi $Y$, Hoshino T, Onaya T, Miyazaki S, Kurosawa H, Nakamura T, Ogawa $\mathrm{N}$ (1994) Effects of $1 \alpha$-hydroxyvitamin $\mathrm{D}_{3}$ on lumbar bone mineral density and vertebral fractures in patients with postmenopausal osteoporosis. Calcif Tiss Int 54: 370-376.

5. Shiraki M, Kushida K, Yamazaki K, Nagai T, Inoue T, Orimo H (1996) Effects of 2 years' treatment of osteoporosis with $1 \alpha$-hydroxyvitamin $\mathrm{D}_{3}$ on bone mineral density and incidence of fracture: A placebo-controlled, double-blind prospective study. Endocr J 43: 211-220.

6. Fujita $\mathrm{T}$, Inoue $\mathrm{T}$, Orimo $\mathrm{H}$, Takahashi $\mathrm{H}$, Morita $\mathrm{R}$, Yamamuro T, Yamamoto K, Yoshikawa S (1990) Effects of elcatonin in the treatment of osteoporosis. J Clin Exp Med 152: 261-282 (In Japanese).

7. Orimo H, Fujita T, Onomura $T$, Inoue $T$, Kushida K, Shiraki M (1992) Clinical evaluation of Ea-0167 (Menatetrenone) in the treatment of osteoporosis. Clin Eval 20: 45-100 (In Japanese).

8. Fujita $T$, Orimo $H$, Inoue $T$, Kaneda $K$, Sakurai M, Morita R, Morii H, Yamamoto K, Sugioka $Y$, Inoue A, Hoshino Y, Kawaguchi H, Yamamoto I, Fukase M, Takaoka K (1993) Double-blind multicenter comparative study with alfacalcidol or etidronate disodium in involutional osteoporosis. Clin Eval 21: 261-302 (In Japanese).

9. Fujita T, Yoshikawa S, Ono K, Inoue T, Orimo H (1986) Efficacy and safety of TC-80 (ipriflavone) in the treatment of osteoporosis. J Clin Exp Med 138: 113-141 (In Japanese).

10. Shiraki M, Orimo H (1991) The effect of estrogen and, sex-steroids and thyroid hormone preparation on bone mineral density in senile osteoporosis-A comparative study of the effect of 1 alphahydroxycholecalciferol ( 1 alpha- $\mathrm{OHD}_{3}$ ) on senile osteoporosis. Folia Endocrinol Japon 67(2): 84-95 (In Japanese).

11. Reynolds JJ, Minkin C, Morgan DB, Spycher D, Fleish $H$ (1972) The effect of two bisphosphonates on the resorption of mouse calvaria in vitro. Calcif Tissue Res 10: 302-313.

12. Sato M, Grasser W, Endo N, Akins R, Simmons H,
Thompson DD, Golub E, Rodan GA (1991) Bisphosphonate action. Alendronate localization in rat bone and effects on osteoclast ultrastructure. $J$ Clin Invest 88: 2095-2105.

13. Liberman UA, Weiss SR, Broll J, Minne HW, Quan H, Bell NH, Rodriguez-Portales JR, Downs RW, Dequeker J, Favus M, Seeman E, Recker RR, Capizzi T, Santora II AC, Lombardi A, Shah RV, Hirsch LJ, Karpf DB (1995) Effects of oral alendronate on bone mineral density and the incidence of fracture in postmenopausal osteoporosis. N Engl J Med 333: 1437-1443.

14. Garnero P, Shih WJ, Gineyts E, Karpf DB, Delmas PD (1994) Comparison of new biochemical markers of bone turnover in late postmenopausal osteoporotic women in response to alendronate treatment. J Clin Endocrinol Metab 79: 1693-1700.

15. Orimo $H$ (1989) The diagnostic criteria and prevention of involutional osteoporosis. J Clin Exp Med 148: 808 (In Japanese).

16. Shiraki M, Fukunaga M, Morita R, Orimo H (1991) Cross calibrated standard values of vertebral bone mineral density in Japanese. J Bone Miner Metab 9 (Suppl) I: 44-49.

17. Eguchi H, Hosoda $K$, Kurihara N, Nakamoto $T$, Kobayashi S, Arita M, Hasegawa R, Ohta T, Kiyoki M, Yamaji T, Shiraki M (1995) Sandwich immunoassay specific for the $\mathrm{N}$-terminal sequence of osteocalcin. J Immunol Methods 184: 231-240.

18. Nussbaum SR, Zahradnik RJ, Lavigne JR, Brennan GL, Nozawa-Ung K, Kim LY, Keutmann HT, Wang C-A, Potts JT, Segre GV (1987) Highly sensitive twosite immunoradiometric assay of parathyrin, and its clinical utility in evaluating patients with hypercalcemia. Clin Chem 33: 1364-1367.

19. Black D, Dunkan A, Robins SP (1988) Quantitative analysis of the pyridinium crosslinks of collagen in urine using ion-paired reverse-phase highperformance liquid chromatography. Anal Biochem 169: 197-203.

20. Davis JW, Novotny R, Ross PD, Wasnich RD (1994) The peak bone mass of Hawaiian, Filipino, Japanese, and white women living in Hawaii. Calcif Tissue Int 55: 249-252.

21. Nordin BEC (1966) International patterns of osteoporosis. Clin Orthop Related Res 45: 17-30.

22. Devogelaer JP, Broll H, Correa-Rotter R, Cumming DC, Nagant de Deuxchaisnes C, Geusens P, Hosking D, Jaeger P, Kaufman JM, Leite M, Leon J, Liberman U, Menkes CJ, Meunier PJ, Reid I, Rodriguez J, Romanowicz A, Seeman E, Vermeulen A, Hirsch LJ, Lombardi A, Plezia K, Santora AC, Yates AJ, Yuan W (1996) Oral alendronate induces 
progressive increases in bone mass of the spine, hip, and total body over 3 years in postmenopausal women with osteoporosis. Bone 18: 141-150.

23. Gallagher JC, Riggs BL, DeLuca HF (1980) Effect of estrogen on calcium absorption and serum vitamin D metabolites in postmenopausal osteoporosis. $J$ Clin Endocrinol Metab 51: 1359-1364.

\section{The Alendronate Research Group}

Central Committee: Hajime Orimo, M.D. (Department of Geriatrics, Faculty of Medicine, The University of Tokyo); Kiyoshi Kaneda, M.D. (Department of Orthopedic Surgery, Hokkaido University School of Medicine); Masataka Shiraki, M.D. (Department of Laboratory Medicine, Tokyo Metropolitan Geriatric Hospital); Hiroshi Minaguchi, M.D. (Department of Obstetrics and Gynecology, Yokohama City University School of Medicine); Tetsuo Inoue, M.D. (Department of Orthopedic Surgery, Hamamatsu University School of Medicine); Akio Tomita, M.D. (Department of Clinical Laboratories, Aichi Medical University); Yukihiro Nagata, M.D. (Department of Obstetrics and Gynecology, Faculty of Medicine, Kagoshima University).

Bone Mass Assessment Committee: Masao Fukunaga, M.D. (Department of Radioisotope, Kawasaki Medical School); Kazuhiro Kushida, M.D. (Department of Orthopedic Surgery, Hamamatsu University School of Medicine); Masataka Shiraki, M.D., (Department of Laboratory Medicine, Tokyo Metropolitan Geriatric Hospital); Hideaki Kishimoto, M.D. (Department of Orthopedic Surgery, Faculty of Medicine, Tottori University).

Controller: Mitsuyoshi Nakashima, M.D. (Department of Pharmacology, Hamamatsu University School of Medicine).

Medical institutions: Kiyoshi Kaneda, M.D., Shigenobu Sato, M.D., Yoshihiro Hosokawa, M.D. (Department of Orthopedic Surgery, Hokkaido University School of Medicine); Shigeo Matsuno, M.D., Tadanori Oguma, M.D. (Department of Orthopedic Surgery, Bibai Workmen's Accident Compensation Insurance Hospital); Akira Yajima, M.D., Takao Fukaya, M.D., Midori Tamura, M.D. (Department of Obstetrics and Gynecology, Tohoku University School of Medicine); Jun Ishii, M.D., Akira Itabashi, M.D. (Department of Internal Medicine IV, Saitama Medical College); Hajime Orimo, M.D., Iyoshi Ouchi, M.D., Takayuki Hosoi, M.D., Yuzo Mizuno, M.D. (Department of Geriatrics, Faculty of Medicine, The University of Tokyo); Masataka Shiraki, M.D., (Department of Laboratory Medicine, Tokyo Metropolitan Geriatric Hospital); Katsuhiko Hasumi, M.D., Jui-Tung Chen, M.D., Yumiko Seimiya, M.D. (Department of Gynecology, Japanese Foundation for Cancer Research); Hiroshi Minaguchi, M.D., Michiyoshi Taga, M.D., Michiko Yamanaka, M.D., Syuya Sakakibara, M.D. (Department of Obstetrics and Gynecology, Yokohama City University School of Medicine); Toshimasa Onnaya, M.D., Kazuho Ohta, M.D. (Department of Internal Medicine III, Yamanashi Medical College); Noriya Akamatsu, M.D., Ikumasa Nakajima, M.D. (Department of Orthopedic Surgery, Yamanashi Medical College); Junzo Kato, M.D., Toshihiko Kinoshita, M.D. (Department of Obstetrics and Gynecology, Yamanashi Medical College); Tetsuo Inoue, M.D., Kazuhiro Kushida, M.D., Kaoru Yamazaki, M.D. (Department of Orthopedic Surgery, Hamamatsu University School of Medicine); Toshihiko Terao, M.D., Hiroshi Noto, M.D. (Department of Obstetrics and Gynecology, Hamamatsu University School of Medicine); Akira Machida, M.D. (Department of Orthopedic Surgery, Fujinomiya City Hospital); Katsunori Ohya, M.D. (Department of Orthopedic Surgery, Narita Memorial Hospital); Masami Nakanishi, M.D., Tetsuo Masahashi, M.D., Yoshizumi Negoro, M.D. (Department of Obstetrics and Gynecology, Aichi Medical University); Shigeo Niwa, M.D., Fujimaru Takayanagi, M.D. (Department of Orthopedic Surgery, Aichi Medical University); Akio Tomita, M.D. (Department of Clinical Laboratories, Aichi Medical University); Tsunenori Takano, M.D., Hiroshi Tanaka, M.D. (Department of Internal Medicine, Social Insurance Chukyo Hospital); Yoshiaki Yamada, M.D. (Department of Orthopedic Surgery, Social Insurance Chukyo Hospital); Kingo Sahara, M.D., Masami Osawa, M.D. (Department of Obstetrics and Gynecology, Social Insurance Chukyo Hospital); Rikushi Morita, M.D. (Department of Radiology, Shiga University of Medical Science), Hiroji Okada, M.D., Hideo Honjo, M.D., Kazunori Tanaka, M.D. (Department of Obstetrics and Gynecology, Kyoto Prefectural University of Medicine); Soji Maruo, M.D., Kosei Yo, M.D., Keizo Nakano, M.D. (Department of Orthopedic Surgery, Hyogo College of Medicine); Kichizo Yamamoto, M.D., Hideaki Kishimoto, M.D. (Department of Orthopedic Surgery, Faculty of Medicine, Tottori University); Naoki Terakawa, M.D., Takashi Ito, M.D. (Department of Obstetrics and Gynecology, Faculty of Medicine, Tottori University); Masao Fukunaga, M.D., Shimato Ono, M.D. (Department of Radioisotope, Kawasaki Medical School); Ryo Watanabe, M.D., Hiroko Imai, M.D. (Department of Orthopedic Surgery, Kawasaki Medical School); Yusuke Sagara, M.D., Yuji Okatani, M.D. (Department of Obstetrics and Gynecology, Kochi Medical School); Hitoo Nakano, M.D., Masahiro Nozaki, M.D. (Department of Gynecology and Obstetrics, Faculty of Medicine, Kyushu University); Yoichi Sugioka, M.D., Syuya Kawamura, M.D. (Department of Orthopedic Surgery, Faculty of Medicine, Kyushu University); Yukihiro Nagata, M.D., Syoichiro Kosya, M.D. (Department of Obstetrics and Gynecology, Faculty of Medicine, Kagoshima University). 